\title{
EDITORIAL
}

\section{New Year's Message}

\author{
Yi QIAN (凶) \\ School of Environment, Tsinghua University, Beijing 100084, China
}

(C) Higher Education Press and Springer-Verlag Berlin Heidelberg 2012

With the arrival of 2012, the journal of Frontiers of Environmental Science \& Engineering in China has stepped into the sixth year since its birth. It is a great pleasure to express sincere thanks to all of our authors, editors, reviewers and readers who have supported us for the past five years, and wish you have a very promising and happy new year.

Environmental issues draw global attention. China is also very concerned about these issues, and has strengthened communication and cooperation with other countries. The goal of our journal is to provide an international communication platform of high quality. Here I am pleased to announce two pieces of good news. First, our journal will change its name from the Frontiers of Environmental Science \& Engineering in China to the Frontiers of Environmental Science \& Engineering, representing a step forward as an international journal. Second, the journal will change from a quarterly to a bi-monthly journal in order to provide more opportunities for environmental researchers to communicate and to publish their excellent works.

In 2011, we have selected three best papers as The Annual Best Paper in recognition for the most influential papers and with an aim to promote the basic knowledge of environmental sciences and the development of engineering technologies. In 2012, we will continue with The Annual Best Paper contest in order to draw more attention to the journal, and to encourage innovations in the environmental fields. Meanwhile, we will continue to make efforts to further improve our journal.

Again, we would like to express our heartfelt thanks for your support. In 2012, we will improve the quality and scientific impact of our journal, and provide more opportunities for environmental researchers to communicate. We desire your further support to build a high-quality journal platform!

Yi QIAN

Editor-in-Chief

Received December 20, 2011

E-mail: qiany@tsinghua.edu.cn 